\title{
CONFRONTING CHALLENGES IN IMPLEMENTING E-PORTFOLIO VIA FACEBOOK IN A PHILIPPINE UNIVERSITY
}

\author{
Philippe John F. Sipacio \\ National University, Manila, Philippines \\ De La Salle University, Manila, Philippines \\ email: pjsipacio@yahoo.com.ph; pjsipacio@gmail.com
}

Article received: 10 August 2014

Final proof received: 6 December 2014

\begin{abstract}
As an alternative assessment, e-Portfolio via Facebook (evFb) has been introduced at De La Salle University (DLSU) specifically at Department of English and Applied Linguistics (DEAL) primarily to respond to the demands of $21^{\text {st }}$ century literacy. However, it was observed that despite the positive impact of evFb on students based on pilot-testing and related studies, there were still innumerable challenges that hindered its implementation. In this paper, these problems were identified, and were addressed using the lens of participatory development framework. Data were taken from interview and feedback forms of participants namely institution (represented by the department chair and project/program committee), implementers/teachers, and students, and were subjected to content analysis. The results showed three major issues classified as: (1) strong apprehension of students to publish their writing outputs on-line; (2) resistance of teachers towards FB as an educational tool; and, (3) concerns of institution as regards academic honesty and identity theft on-line. To confront these challenges and ensure effective implementation and sustainability of evFb at DEAL, improving participatory mechanisms was suggested and discussed. Finally, some opportunities and implications for policy relevant to evFb were also presented.
\end{abstract}

Keywords: e-Portfolio, Facebook, alternative assessment, participatory development

Recent studies on pedagogy postulate that institutions, teachers, and students are required to possess a wide range of abilities, competitiveness, and competencies to triumph in the $21^{\text {st }}$ century. Accordingly, there have been a series of alignment in the aspects of education to ensure that these are properly addressed. As a result, a framework for century learning is conceived highlighting the $21^{\text {st }}$ century student outcomes. One of the core themes is information, media, and technology, which demand high level of information literacy, media literacy, and Information and Communications Technology (ICT) literacy. This has consequently reshaped the academic goals of every national and international institution particularly DLSU.

Supporting the thrusts of DLSU, DEAL has already begun to design and implement programs that address the needs of the $21^{\text {st }}$ century literacy environment. In fact, it has a considerable number of research-based practices in terms of continuum instruction and learning. More significantly, it has started to implement alternative assessment tools namely portfolio and performance-based assessment fostering student awareness of and engagement in learning. Recently, DEAL has introduced a novel assessment, i.e. evFb taking advantage of the increasing availability and popularity of digital forms and social networking sites. The initiative is researchbased, and underwent several pilot tests before it was implemented. Nevertheless, despite the high level of impact and positive feedback it gained based on empirical studies, evFb still did not get the impression it should at DEAL. 


\section{Facebook in Education}

The considerable number of users of FB has led educators to utilize FB for communicating with their students (Grant, 2008; as cited in Donmus, 2010). In the study of Kabilan, Ahmad, and Abidin (2010), the findings showed that the students perceived FB as an online environment to expedite language learning specifically English. Similarly, Donmus (2010) asserts that educational games on FB fecundate learning process and make students' learning environment more engaging. Likewise, the same study reveals that FB could be used as a tool which could aid individuals to execute a range of social acts through social literacy implementation (ibid).

Meanwhile, the study of Wang, et al. (2012) explored the effectiveness of FB as learning management system (LMS). The results of their study suggest that FB can be used as an effective LMS for language teaching and learning. Kabilan, et al. (2010), on the other hand, explored the direct or indirect activities of FB users. However, using the Facebook group as an LMS has certain limitations as shown by the study of Wang, et al. (2012). For instance, FB LMS did not support other format files to be uploaded directly, and the discussion was not organized in a threaded structure. Also, the students did not feel safe and comfortable as their privacy might be revealed. On their part, teachers have a neutral attitude towards the acceptance of FB as a safe environment for accessing education materials and they feel strongly against lecturing courses via FB (Tiryakioglu \& Erzurum, 2011).

In a review of related studies and literatures by Grosseck, Bran, and Tiru (2011), it was revealed that FB could contribute considerably to the quality of education:

For students: (1) To build motivation, interaction and engagement among learners (Metz, \& Albernhe-Giordan,, 2010); (2) To gain effective and efficient transfer of knowledge (Murphy, 2011).; (3) To hone affirmative attitude towards learning (Pasek \& Hargittai, 2009); (4) To hone communication, cognitive and social competencies (Bosch, 2009;).

For teachers: (1) To develop the competency of teachers in teaching diverse and contemporary student (Kabilan, 2010; Ophus \& Abbitt, 2009); (2) To utilize diagnostic formative evaluation effectively (Pasek \& Hargittai, 2009); (3) To be adept in psychosocial competencies of interaction and communication (Selwyn, 2009); (4) To maximize the integration of the information coming from formal/nonformal/informal sources (Bosch, 2009) (pp. 1426-1427).

Although the stated comprehensive list asserts that the utilization of ICT, specifically $\mathrm{FB}$, has proven its effectiveness, the study of Beer, Jones, and Clark (2009) found that students still use FB more for social uses and less for academic purposes even if they use it as LMS.

\section{evFb as an Alternative Assessment}

Another impact of ICT in education is in assessment. In contrast to traditional learning, nowadays, own learning is one of the responsibilities of students apart from planning their own educational process. This led teachers to come up with alternative assessment methods through which the learners can be responsible for keeping track of their performance. This necessitated veering away from the traditional paper-andpencil tests which mainly involve memorization. Alternative assessment methods likewise counter the short-term learning and poor work habits which educators criticize in the "traditional sit-down exam" (Gibbs, 1994; Shepard, 2001 as cited in Dysthe, Engelsem, \& Lima, 2007). Alternative assessments use more extended and open-ended forms such as assignments, projects, and practical activities in measuring students' learning (Berry, 2008). One form of 
alternative assessment method that is gaining popularity is the e-portfolio. Challis (2005 as cited in Alexiou \& Paraskeva, 2010) defined e-portfolio as

a selective and structured collections of information, gathered for specific purposes, showing/evidencing one's accomplishments and growth ... stored digitally and managed by appropriate software, developed by using appropriate multimedia and customarily within a web environment and retrieved from a website, or delivered by cd-rom or by dvd (p.3049).

An e-portfolio system or combination of tools that supports reflection, collaborative activity and the preparation and presentation of evidence of achievement provides crucial opportunities for personal development (Joint Information Systems Committee [JISC], 2008, p.8).

The main goal of an e-portfolio is "to collect evidence for summative assessment, to demonstrate achievement, to record progress... to nurture a continuing process of personal development and reflective learning, more commonly experienced in higher and continuing education contexts" (JISC, 2008, p.4). An advantage of the e-portfolio is it allows the learners to reorganize or revise their works.

Alternative assessment is one way of motivating students to be responsible for their own learning (Berry, 2008). With this responsibility e-portfolio could be used as educational tool. E-portfolio provides permanent learning (Akcil \& Arap, 2009), or life-long learning (Baris \& Tosun, 2011) as opposed to short-term learning.

According to Akcil and Arap (2009), several advantages can be provided by eportfolio: (1) students are encouraged to display their educational acquisition and expectancies, (2) students exhibit their own development by organizing learning materials,
(3) students find an opportunity to hone their capability in the subject of 'knowledge and communication technologies', (4) students easily share their works with teacher, friends, and other people concerned, and (5) students get feedback easily and this gives a way for own development and own assessment. For example, the study of Alexiou and Paraskeva (2010) provides a positive feedback from the students as they become engaged and enthusiastic during e-portfolio process. Furthermore, they assert the implementation of e-portfolio as a tool for self-regulated learning for students' empowerment as active learners (ibid).

The studies of Genc and Tinmaz (2010) used the e-portfolio in computer education and assert that it is more suitable for project-based evaluation. Another computer course asserts that e-portfolio is beneficial for students (Metz \& Albernhe-Giordan, 2010). E-portfolio is not only advantageous in computer courses but also in writing courses. For instance, the study of Romova and Andrew (2011) finds eportfolio as effective assessment tool for academic writing. The participants in the study of Kabilan and Khan (2012) found that e-portfolio is an effective monitoring tool as they monitor their performance and achievements. Furthermore, the self-efficacy of the participants who utilized e-portfolio in the study of Nicolaidou (2012) increased significantly. Findings in the study of Lam (2013) revealed that metacognition was enhanced in the portfolio compilation of EFL students. The study of Alexiou and Paraskeva (2010) showed that the e-portfolio implementation garnered a positive feedback from the students since the e-portfolio has been a significant contribution as they succeed to become engaged and enthusiastic during eportfolio process. Self confidence of students also increases in case e-portfolios are used for evaluation purposes (Akcil \& Arap, 2009). On the other hand, Kabilan and Khan's (2012) study on the e-portfolio as a learning 
monitoring tool noted some challenges regarding the use of the e-portfolio which include validity and reliability, interrupted Internet connection, negative attitudes participants, time constraints, workload and ethical issues.

In the Philippine context, the paper of Valdez (2010) on college students' use of the e-portfolio yielded two interesting findings. First, using the e-portfolio enabled the students to document their growth as writers; it allowed them to write about issues, not mere topics, which they think would interest their audience more. The use of SNSs exposed the students to a wider range of audience, not just their peers and teachers. Likewise, the use of SNSs gave them a sense of anonymity and kept them from being directly confrontational. Second, using the e-portfolio enabled the students to use different media in presenting their written outputs.

Thus far, what has been presented is how ICT and SNSs like FB in particular have found its use in the classroom to facilitate or enhance learning. Likewise the merits of the e-portfolio as an alternative assessment have been discussed. However, after reviewing the articles on ICT, SNSs as pedagogical tools and e-portfolio as an alternative assessment method, there are apparently no studies conducted which explores the use of FB as an e-portfolio.

\section{Participatory Development Framework}

Several scholars have increasing interests on the framework of participatory development and most of them share a common ground as regards its concept. Stiglitz (2002), for instance, argued that this is significant to achieving success in a knowledge-based economy. He further contends that "consensus-building, open dialogue, and promotion of an active civil society are key ingredients to long term sustainable development" (p. 165). In short, it necessitates transformation to a society while acknowledging the participation of the citizens, engaging them to a process of politically sustainable economic policies.

Moreover, participatory development is best used to enhance development initiatives such as poverty alleviation, gender empowerment, among others. According to Parfitt (2004) once the citizens are proactive in the relevant initiatives, the goals of development are achievable. In fact, the concept is empowering the citizens by making them involved in identifying and analyzing their needs, and in providing possibilities that can address those.

Several approaches to participation and development were provided by McGee (2002). These, however, have the same central objective, i.e. to enhance the life of the poor. Some of these methods pioneered and promoted by official agencies such as stakeholder analysis, social analysis, beneficiary assessment and logical framework analysis. Others are toolkits applied by planners or implementers to the stakeholder population are characterized either by promotion of participation, or by the performing of a "research market" role, checking on the suitability of the interventions for a particular group. However, the ones prominent are known as the major body of participatory approaches which sought to enable people to share, enhance, and analyze their knowledge of life and conditions, to plan and act (Chambers, 1994 in McGee, 2002, p. 99). This is referred to as Participatory Rural Appraisal (PRA) which the main precursor to PRA (developed to address the limitations of RRA, open up other fundamentals of development, to scrutinize, critique and ownership by the poor and powerless people) is the Rapid Rural Appraisal (RRA) which emerged in answer to Cernea's cry for sociological methods and Chamber's concerns on rural development tourism. The context of these approaches, however, is social development. It is the intent of this paper to 
make an attempt to pick some striking features of these approaches that might be relevant in evaluating evFb.

On the other hand, active participation of the citizens in development contributes to a sound and reasonable government's decisions. Irvin and Stansbury (2004) assert the advantages of participation in decision making to both the participants and the government in terms of the process and outcomes.

Moreover, Cornwall (2000) supported a premise on "participation efforts", bringing about participation in development and embracing a range of contrasting perspectives and methods. This contention has varied implications for how participation and participants come to be constructed, as well as for the part participation is held to play in the development process.

Distinguishing between forms of participation that work through enlistment and those that genuinely open up the possibilities for participants to realize their rights and exercise voice is therefore important, for these differences are something that blanket critiques of participation tend to disregard.

As regards the present study, to the knowledge of the researcher, there is a dearth in research on using participatory development framework in education particularly in language teaching and learning. Hence, this study was conducted. The present study focuses on identifying the challenges derived from the responses of the participants, and addressing them through the lens of participatory development framework.

\section{METHOD}

This present study used interview and content analysis of the feedback from participants comprise of institution (represented by the department chair and project/program committee), implementers/ teachers, and students. Emphasis was placed, in consideration of the objectives of this study and practicality of interpreting text with the potential for multiple meanings, within qualitative methods. Statements from the survey forms of the participants were used as unit of analysis.

Content analysis offers an approach to data analysis that centers largely on the researcher's conception of the object of analysis, that is, the content. How the content is conceived remains an important consideration in developing a framework, including the purpose and processes, for the analysis. Among the scholarly literature regarding content analysis, three types of definitions surfaced, and each type of definition led to a specific conceptualization of not only the data to be analyzed but also the particular manner in which the analysis may proceed. Krippendorff (2004) has located definitions of content analysis among those that take content

1. to be inherent in a text;

2. to be a property of the source of a text; and,

3. to emerge in the process of a researcher analyzing a text relative to a particular context (p. 19).

\section{Context of Study}

The context of study is DEAL which has been cited by Commission on Higher Education (CHED) as the Center of Excellence in English. Under the Brother Andrew Gonzales, FSC-College of Education (BAG-CED), DEAL offers programs in the graduate and undergraduate level specializing on applied linguistics. Its mission-vision can be succinctly stated as to develop not only language competent students, but also socially competent ones.

DEAL also has been known in the BAGCED as pioneer in implementing alternative assessments such as performance-based task and portfolio. Specifically, these have been used since 2000. The transition from traditional portfolio to digital portfolio started in 2005 when the said department intended to 
encourage teachers to employ paperless practice. Then at the height of the popularity of microblogging sites and SNSs, some teachers have gradually introduced ePortfolio. It was in first term of school year 2012-2013 when DEAL looked into the effectiveness of evFb through a series of pilot testing.

One of the programs of DEAL which is eportfolio (portfolio then) has been required in English Communication (ENGLCOM). ENGLCOM is a 6-unit academic reading and writing course offered to all first year students. It consists of two components namely, Writing Component (WC) and Reading, Viewing and Language Component (RVLC). The contents of e- portfolio include the following:

1. Title Page

2. Cover Letter (Letter to the Reader)

3. ENGLCOM and Portfolio Objectives

4. Entry Essay (Unedited)

5. Extended Definition(WC)

6. Problem-Solution/Argumentative Essay (WC)

7. Exit essay

8. Reflective essay

9. Appendix: Documentary Analysis (RVLC)

\section{RESULTS AND DISCUSSION}

Based on the statements in the feedback form and interview to the institution (represented by the department chair and project/program committee), implementers/ teachers, and students, the following are the challenges identified in implementing this initiative. These three were the ones highly stated/emphasized by the participants.

\section{Students' Apprehension}

There is a "strong" apprehension of students to publish their writing outputs on-line. This proposition seems to indicate that e-portfolio can trigger anxiety among students, knowing that other people including their families and friends will be reading their work, as can be seen in the comments of the students written in the feedback form. Some examples of students' feedback are the following.

1. The publishing component in eportfolio is highly problematic to students with very low self-esteem in writing.

2. Only those who can write well have the guts to make their writing outputs public.

3. If one's writings posted on FB are distasteful to readers, they might cause a venue for bashing.

In addition, teachers understand the fact that these students are not used to presenting their work to others via on-line based on the comments by the teacher-respondents. Some of these comments are the following.

1. In most cases, there will be negative feedback which students are not prepared of. This might be misinterpreted by the students and might cause anxieties to them.

2. As can be observed, students need to be motivated to present their work online and be prepared for criticism that their work might get from the audience.

To address this issue, advocates and implementers are constructively advised to support their students, to provide and clarify the objectives and explain exhaustively the advantages of evFb, so they can guarantee positive perceptions from them.

\section{Teachers' Resistance}

There are negative perceptions of teachers toward FB as an educational tool. For one, it has very limited education-related activities because it was not designed for academic purposes. This contention is supported by the empirical study conducted by Murphy (2011). The results showed that students perceived FB purely as a SNS- a tool to get away from doing academic work. Furthermore, Selwyn (2009 in Grosseck, Bran, \& Tiru, 2011) claimed that the education-related use of FB 
tended to focus on administrative matters such as lecture schedules, assignments requirements rather than pedagogical.

Another apprehension of the teachers is the attitude of students toward FB. Based on experiences, three teachers agree that communicating through FB was viewed by their students as nonacademic.

Next is the debilitating problem as regards the resistance of teachers on the use of technology. Some teachers still rely on the traditional forms of practices. Though majority of them have laptops and desktop computers, their capacity to use social networking sites also vary. Also, their access to computers and online connection have been problematic due to weak internet connection at workplace and home, limited availability of computer terminals at school, and competing requirements in other teaching assignments.

\section{Concerns of the Institution}

There is a big concern of the institution as regards the implications of e-Portfolios containing materials that might bring charges such as plagiarism when published, or leave authors open to the possibility of identity theft on-line. If students are ineffectively trained to be academically honest with their works, there is a tendency for them to commit the act. Consequently, this affects the quality of ePortfolio and the goal of the institution of becoming a front-liner in producing high impact research outputs. Hence, there is a need to have more initiatives such as intensive campaign programs or awareness on academic honesty and scholarly outputs.

\section{Confronting Challenges through \\ Participatory Development}

Acknowledging the importance of the participation development framework in addressing these gaps, one can contend that there is a need to re-examine the decision process and outcomes and modes of participation in the student evFb towards its successful implementation.

With regard to the challenges identified and discussed above, it is very important to consider these as an opportunity rather than a threat. This is to aid the implementers and advocates of this alternative assessment to easily identify and clarify unexplained and perplexing ideas, thoughts and discussions that critically need elucidation and exemplification. However, this can be done through an active participation of not just the implementers and advocates but also by the institution and students. In turn, everybody can benefit from each other through an informative dialogue or exchange of intellectual discourse (Irvin \& Stansbury, 2004; Stiglitz, 2002). Consequently, trust with each other is built, which is very essential in an effective project implementation.

Additionally, in the process of the implementation of this initiative, it is very important to clarify and strengthen the modes of participation of the institution, implementers/teachers, and students. To illustrate, as functional mode suggests, the students, who will serve as the beneficiary need to be assured of clear benefits over issues and concerns of this project. Hence, there should be changing dynamics in giving assistance in terms of discussing to students the processes and advantages of the alternative assessment. In this case, compliance from the students may be secured.

Another, to enhance responsiveness (Irvin $\&$ Stansbury, 2004), there is a need to solicit suggestions, contributions, and/or recommendations from the participants, which should be an on-going observation. The acknowledgement of their ideas to this project will lead towards an effective practice; hence, a consultative mode of participation is also necessary.

Meanwhile, the institution and implementers/teachers need to be delegated with responsibilities to make this project run 
more smoothly and efficiently by enlisting contributions and delegating responsibilities. The role of the former, for example, is to help with student transition, give an insight into student progression through a specific course or in general, offer the opportunity for dynamic course feedback from students, help to support work placements by showcasing student achievement it can also demonstrate the success of the institution and encourage institutional reflection and improvement, while the role of the latter is to show the possible positive outcomes to the venture and examples of best practice, see this as being in the interests of the student support and training to acquire the appropriate skills to support students including technical skills and giving feedback and go through the process of creating an e-portfolio themselves. The above illustrations are salient in building political capabilities, critical consciousness and confidence and enhancing accountability (ibid, 2004) among the participants involved.

To address the challenges in the implementation of this initiative as discussed above, perspectives from the participation development framework can be used. Table 1 presents the summary.

Generally, implementers/advocates should consider assessment of current practices pertaining to e-Portfolio within the department. Specifically, they should have to:

1. determine the extent to which this initiative is currently being practiced within the department;

2. consider unique characteristics of different disciplines, academic units and office within DLSU;

3. assess alignment with the current learning and teaching framework of DLSU, identify "best practices", and adapt or develop a metrics for evaluating this project;

4. develop a unified framework for ePortfolio as well as a structure/mechanism for its implementation; and

5. disseminate results of the study and utilize these to develop a plan for subsequent projects. Whatever the outcomes are, these should be presented/shared by the implementers/ advocates with other stakeholders who will be directly involved or affected by this project to gain insights, and feedback for an effective implementation.

Table1. Participatory Development Perspectives in Addressing the Challenges in e-Portfolio via Facebook

\begin{tabular}{ll}
\hline \multicolumn{1}{c}{ Challenges } & \multicolumn{1}{c}{ Participatory Development Perspectives } \\
\hline $\begin{array}{l}\text { Apprehension of } \\
\text { students to }\end{array}$ & $\begin{array}{l}\text { - Both the institution and the implementers should collaborate in } \\
\text { providing strong support to students by providing clear benefits of } \\
\text { publish their }\end{array}$ \\
$\begin{array}{ll}\text { priting outputs } \\
\text { on-line }\end{array}$ & $\begin{array}{l}\text { - Suggestions from the students should be sought, and appropriate actions } \\
\text { to these may be taken. } \\
\text { - Stakeholders should consider student's apprehensions as an opportunity } \\
\text { to develop more effective mechanisms in participation development } \\
\text { towards the effective implementation of the project. }\end{array}$ \\
$\begin{array}{l}\text { Resistance of } \\
\text { teachers toward }\end{array}$ & $\begin{array}{l}\text { The institution should allow the teachers to discuss all these negative } \\
\text { perceptions during the open dialog and attempt to explore the causes of } \\
\text { FB as an }\end{array}$ \\
these.
\end{tabular}


collaborative efforts. As regards teachers whose apprehension is on the use of FB, they should be asked on what alternative platform may be more convenient or appropriate for them. Then if there may be other options or platforms, they will be encouraged to share and present the features and guidelines of these.

- Defining a teacher profile based on competencies may be done. The participatory method of co-construction of the teacher profile linked to evidence of the competencies allows the definition of processes for good evidence and good practice acted by the teachers related to the areas of competence. These practices are subjected to self-assessment by the teacher and/or external ways of assessment that could occur by mentors, colleagues, external experts and students.

Concern of the institution as regards academic honesty and identity theft online
- The institution should strengthen its efforts in advocating academic honesty by developing relevant programs. The program designs may be sought from the stakeholders involved in this initiative.

- There should be more effective mechanisms and framework to promote original and novel works of students.

\section{CONCLUSION}

This study identified the challenges that confronted the implementation of $\mathrm{evFb}$ at DEAL, DLSU. Generally, the results showed that the participants are not homogenous as to the use of evFb as a form of assessment. Three major statements were highlighted, namely (1) the strong apprehension of students to publish their writing outputs on-line; (2) the negative perceptions of teachers towards FB as an educational tool; and, (3) the concern of the institution as regards academic honesty and identity theft on-line. To ensure effectiveness in implementing and sustaining $\mathrm{evFb}$ at DEAL, improving participatory mechanisms was suggested and discussed.

To replicate this study years later might be of interest. Research and development opportunities might be in terms of professional development and for teachers and staff in developing, promoting and integrating digital technologies relevant to language teaching and learning in curriculum. Another is evaluating prevailing and emerging frameworks and policies on the role of ICT in education in the context of $21^{\text {st }}$ century literacy.

\section{REFERENCES}

Akçıl, U., \& Arap, I. (2009). The opinions of education faculty students on learning processes involving e-portfolios. Procedia Social and Behavioral Sciences, 1, pp. 395-400. doi:10.1016/j.sbspro.2009.01.071.

Alexiou, A., \& Paraskeva, F. (2010). Enhancing self-regulated learning skills through the implementation of an eportfolio tool. Procedia Social and Behavioral Sciences, 2, pp. 3048-3054. doi:10.1016/j.sbspro.2010.03.463.

Beer, C., Jones, D. \& Clark, K. (2009). The indicators project identifying effective learning: Adoption, activity, grades and external factors. Retrieved from http://ascilite.org.au/conferences/auckland 09/procs/beer.pdf

Berry, R. (2008). Assessment for learning. HongKong: HongKong University Press.

Bosch, T. E. (2009). Using online social networking for teaching and learning: Facebook use at the University of Cape Town. Communicatio: South African 
Journal for Communication Theory and

Research, 35(2), pp. 185-200.

Cornwall, A. (2000) Beneficiary, consumer, citizen: perspectives for participation for poverty reduction, Sida Studies No. 2 , Stockholm: Sida.

Cornwall, A. (2003). Whose voices? Whose choices? Reflections on gender and participatory development. World Development, 31(8), pp. 1325-1342.

Donmus, V. (2010). The use of social networks in educational computer-game based foreign language learning. Procedia Social and Behavioral Sciences, 9, pp. 1497-1503.

Dysthe, O., Engelsen, K. S., \& Lima, I. (2007). Variations in portfolio assessment in higher education: Discussion of quality issues based on a Norwegian survey across institutions and disciplines. Assessing Writing, 12, pp. 129-148. doi:10.1016/j.asw.2007.10.002.

Genc, Z. \& Tinmaz, H. (2010). A reflection of pre-service teachers on e-portfolio assessment. Procedia Social and Behavioral Sciences, 9, pp. 1504-1508. doi:10.1016/j.sbspro.2010.12.356

Grosseck, G., Bran, R., \& Tiru, L. (2011). Dear teacher, what should I write on my wall? A case study on academic uses of Facebook. Procedia Social and Behavioral Sciences, 15, pp. 1425-1430.

Irvin, R., \& Stansbury,.J. (2004). Citizen participation in decision making: Is it worth the effort?" Public Administration Review, 64(1), pp. 55-65.

Joint Information Systems Committee (JISC) (2008). Effective practice with ePortfolios: Supporting 21st century learning. InfoKit on ePortfolios.

Retrieved from http://teaching.unsw.edu.au/printpdf 568

Kabilan, M., Ahmad, N. \& Abidin, M. (2010). Facebook: An online environment for learning of English in institution of higher education. Internet and Higher Education, 13, pp. 179-187.

Kabilan, M., \& Khan, M. (2012). Assessing pre-service English language teachers' learning using e-portfolios: Benefits, challenges and competencies gained. Computers \& Education, 58, pp. 10071020.doi:10.1016/j.compedu.2011.11.011

Krippendorff, K. (2004). Content Analysis: An Introduction to Its Methodology (2nd ed.). Thousand Oaks, CA: Sage

Lam, R. (2013). Two portfolio systems: EFL students' perceptions of writing ability, text improvement, and feedback. Assessing Writing, 18, pp. 132-153. doi:10.1016/j.asw.2012.10.003

McGee, R. (2002). Participating in development. In U. Kothari and M. Minogue (Eds). Development theory and practice: Critical Perspectives. Hampshire: Palgrave, pp. 92-116.

Metz, S. \& Albernhe-Giordan, H.(2010). EPortfolio: a pedagogical tool to enhance creativity in student's project design. Procedia Social and Behavioral Sciences, 2, pp. 3563-3567. doi:10.1016/j.sbspro.2010.03.552 .

Murphy, L. (2011). Why am I doing this? Maintaining motivation in distance language learning. In T. Lamb, G. Murray, and X. Gao (Eds.), Identity, motivation and autonomy in language learning. Bristol, U.K., Tonawanda, NY, U.S.A. and North York, Ontario, Canada: Multilingual Matters, pp. 107-124.

Nicolaidou, I. (2012). Can process portfolios affect students' writing self-efficacy? International Journal of Educational Research, 56, pp. 10-22. doi:10.1016/j.ijer.2012.08.002

Ophus, J. D., \& Abbitt, J. T. (2009). Exploring the potential perceptions of social networking systems in university courses. Journal of Online Learning and Teaching, 5(4), pp. 639-648. 
Parfitt, T. (2004). The ambiguity of participation: A qualified defense of participatory development. Third World Quarterly, 25(3), pp. 537-556.

Paris, M. F., \& Tosun, N. (2011). E-portfolio in lifelong learning applications. Procedia - Social and Behavioral Sciences, 28, pp. 522-525. doi:10.1016/j.sbspro.2011.11.100.

Pasek, J. \& Hargittai, E. (2009, May 4). Facebook and academic performance: Reconciling a media sensation with data. First Monday, 14(5).

Romova, Z. \& Andrew, M. (2011). Teaching and assessing academic writing via the portfolio: Benefits for learners of English as an additional language. Assessing Writing, 16, pp. 111-122. doi:10.1016/j.asw.2011.02.005

Selwyn, N. (2009b). Face working: Exploring students' education-related use of Facebook. Learning, Media and Technology, 34(2), pp. 157-174. http://dx.doi.org/10.1080/1743988090292 3622

Stiglitz, J. (2002). Participation and development: Perspectives from the comprehensive development paradigm. Review of Development Economics, 6(2), pp.163-182.

Tiryakioglu, F. \& Erzurum, F. (2011). Use of social networks as an educational tool. Contemporary Educational Technology, 2(2), pp. 135-150.

Valdez, P.N. (2010). Reflections on using the digital portfolio in academic writing in a Philippine university: Problems and possibilities. Philippine ESL Journal.5, pp. 160-170.

Wang, Q., Woot, H.L., Quek, C.H., Yang, \& Liu, M. (2012). Using Facebook group as a learning management system: An exploratory study. British Journal of Educational Technology, 43(3), pp. 428438. doi: 10.111/j.1467-

8535.2011.01195.x 